\title{
Remote Sensing Or Global Fire Patterns, Aerosol Optical Thickness, and Carbon Monoxide During April 1994
}
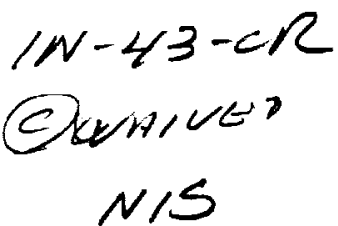

\author{
Sundar A. Christopher ${ }^{1}$, Min Wang ${ }^{1}$, Donna V. Kliche', Ronald M. Welch', Scott Nolf', and Vickie S. Connors ${ }^{2}$ \\ ${ }^{1}$ Institute of Atmospheric Sciences, \\ South Dakota School of Mines and Technology \\ Rapid City, SD 57701 USA \\ ${ }^{2}$ Atmospheric Sciences Division \\ National Aeronautics and Space Administration \\ Langley Research Center \\ Hampton VA 23681 USA
}

Fires play a crucial role in several ecosystems. They are routinely used to bum forests in order to accommodate the needs of the expanding population, clear land for agricultural purposes, eliminate weeds and pests, regenerate nutrients in grazing and crop lands and produce energy for cooking and heating purposes[1]. Most of the fires on earth are related to biomass burning in the tropics, although they are not confined to these latitudes. The boreal and tundra regions also experience fires on a yearly basis. While biomass burning takes place whenever there is plant material that is dry, most fire activities are concentrated between June-October in the Southern hemisphere and between December-April in the Northern hemisphere[2]. Fires alter the state of the vegetation, release large amounts of trace gases, affect the hydrological balance through decrease in evapotranspiration and increased runoff, play a crucial role on tropospheric chemistry due to the gases and particles they release and affect the radiation balance both on regional and global scales. The current study examines global fire patterns, aerosol optical thickness (AOT) and carbon monoxide concentrations during April 9-19, 1994.

Recently, global Advanced Very High Resolution Radiometer (AVHRR) data at nadir ground spatial resolution of $1 \mathrm{~km}$ are made available through the NASANOAA Pathfinder project[3]. These data from April 9-19, 1994 are used to map fires over the earth. Daytime data with equatorial crossing time of 1340 Local Solar time (LST) from NOAA11 during the ascending orbit is used in this investigation. The main reason for choosing this time period is to compare the fire patterns observed by the astronauts aboard space shuttle SRL-1 During this time, global mid-tropospheric measurements of carbon monoxide were also made from the MAPS instrument onboard the same space shuttle. The elevated levels of $\mathrm{CO}$ in the troposphere are often attributed to biomass burning. This provides a unique opportunity to ob- tain fire distributions from independent methods and to compare fire activities with carbon monoxide concentrations measured by MAPS. The AVHRR-derived AOT over oceans are also presented[4]. The AVHRR measures radiation in five spectra channels $(0.58-0.68 \mu \mathrm{m}, 0.725-1.1 \mu \mathrm{m}, 3.55-$

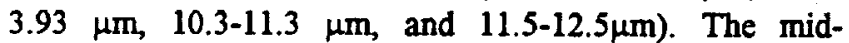
infrared channel (channel 3 ) at $3.7 \mu \mathrm{m}$ is especially suited to detect fires due to the increased radiant energy from fires as opposed to the background.

The pre-processed AVHRR data are first used to eliminate clouds. Then deserts, open water and other water bodies such as lakes and rivers are further screened using available global data bases. Sunglint areas are removed using satellite-sun viewing geometry and for each clear-sky pixel, a series of tests are performed using the near-infrared (channel 2), mid-infrared (channel 3), and infrared channels (channel 4). Fires are characterized by high mid-infrared (channel 1) temperatures (T3>319K) and large mid-IR to infrared temperature (channel 4) differences (T3-T4>15K). $\mathrm{T} 3$ and T4 denote the channel 3 and channel 4 temperatures.

Figure 1 shows the zonal distribution of fires for April 919, 1994. One hundred thirty-nine global strips of AVHRR images were used to create this figure. More than 500 fires were detected in the belt between 10-20N which correspond to fire activities in Africa, Mexico, and the Indo-Buma region. These fire activities correspond to biomass burning due to agricultural practices. A comparison with the Olson ecosystem data base shows the majority of fires are in the savanna, grass shrub, and farm settlement categories. When compared to the Northern hemisphere, the Southern hemi sphere has fewer number of fires because April is the dry season in the Northern hemisphere. Typically, biomass burning fires are observed in the Southern hemisphere between June-October, and between December-April in the 


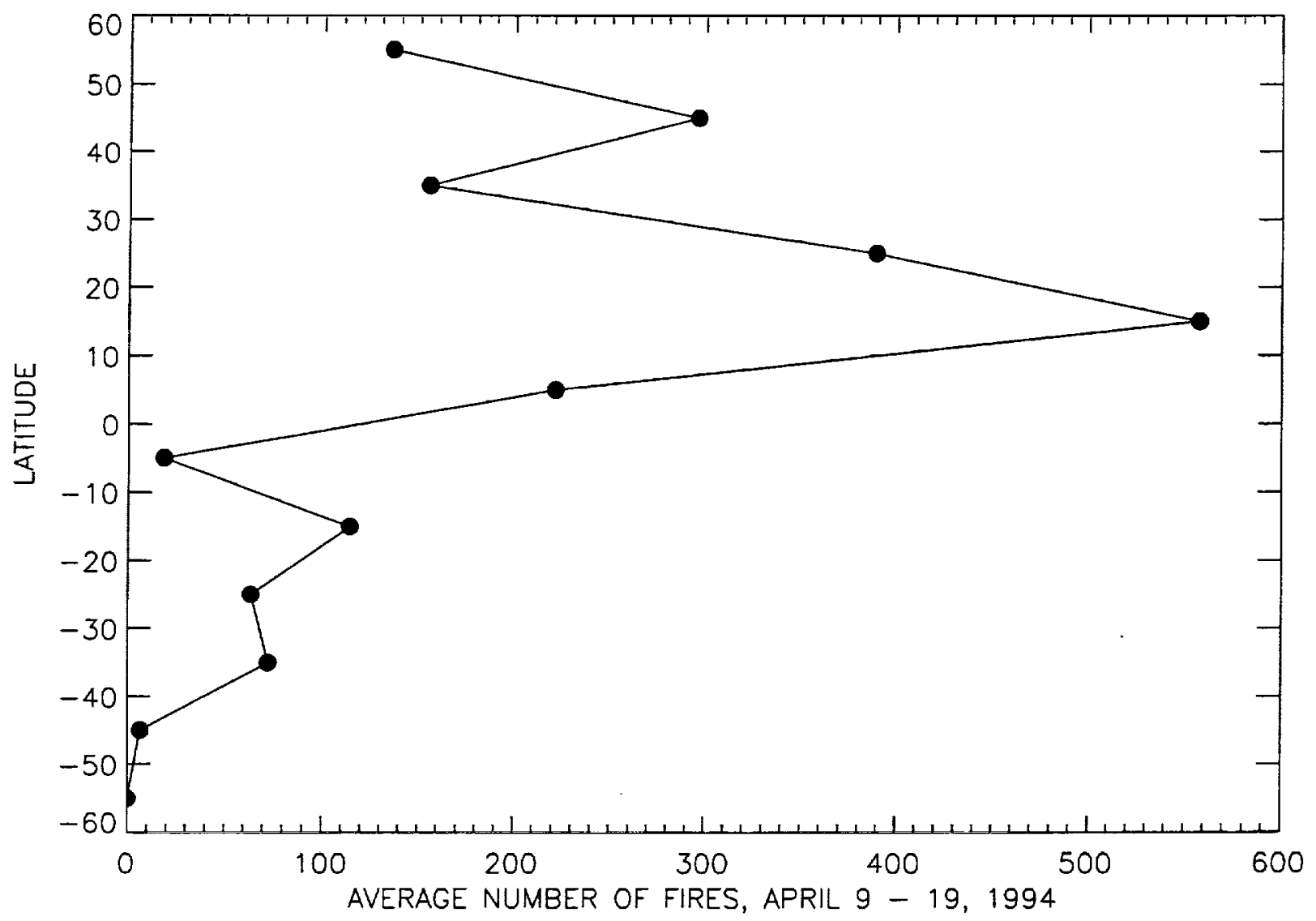

Fig. 1: Zonal distribution of fires for April, 1994.

Northern hemisphere. Fire activities in the Southern hemisphere are in northwest Australia, southeastern Africa, and small regions in South America. Fire counts in the latitudinal belt between $40-50 \mathrm{~N}$ are associated with boreal fires.

Figure 2 shows the latitudinal distribution of MAPSobserved mid-tropospheric $\mathrm{CO}$ along with AVHRR-derived aerosol optical thickness product generated by NOAANESDIS. Note that the aerosol optical thickness values are retrieved only over water surfaces because the aerosols reflect more of the incoming radiation than the underlying background. Also, note that figure 2 is only for the Northem hemisphere because the AOT values are not retrieved in the Southern hemisphere due to solar geometry constraints. Latitudinally-averaged peak aerosol optical thickness values between $0.08-0.09$ are found between $0-20 \mathrm{~N}$ due to the aerosol transport from the biomass burning sources in West Africa into the Eastern Atlantic Ocean and the transport of aerosols from Asia into the Pacific Ocean.
However, note that the MAPS-measured CO concentrations, when averaged over the latitudes, show a steady increase from the equator to $60 \mathrm{~N}$. Average MAPS values in the equatorial belt between $0-20 \mathrm{~N}$ are around $100 \mathrm{ppbv}$ due to the biomass burning activities in West Africa.

Figure 3 shows the longitudinal distribution of MAPSmeasured $\mathrm{CO}$ and AOT derived from the AVHRR. The MAPS measurements show $C O$ values greater than $90 \mathrm{ppbv}$ for the entire globe, which shows the increase of $\mathrm{CO}$ due to biomass burning activities in the Northern hemisphere. High values of $\mathrm{CO}$ are between 170-180E in the Pacific Ocean due to the transport of $\mathrm{CO}$ from Asia. Other high-CO concentrations are found throughout Asia.

In summary, our analysis shows that fires from biomass burning appear to be the dominant factor for increased tropospheric $\mathrm{CO}$ concentrations as measured by the MAPS. The vertical transport of $\mathrm{CO}$ by convective activities, along 


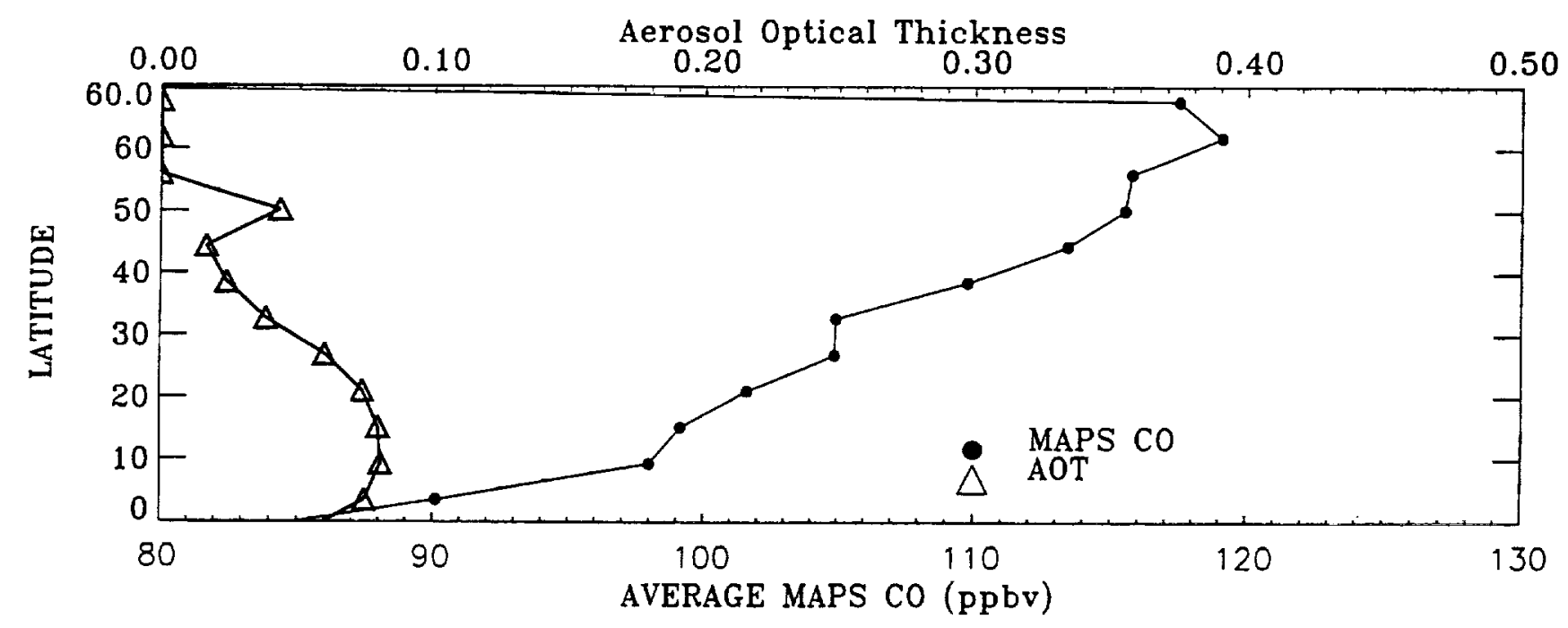

Fig. 2: Zonal distribution of aerosol optical thickness and MAPS measured mid-tropospheric carbon monoxide.

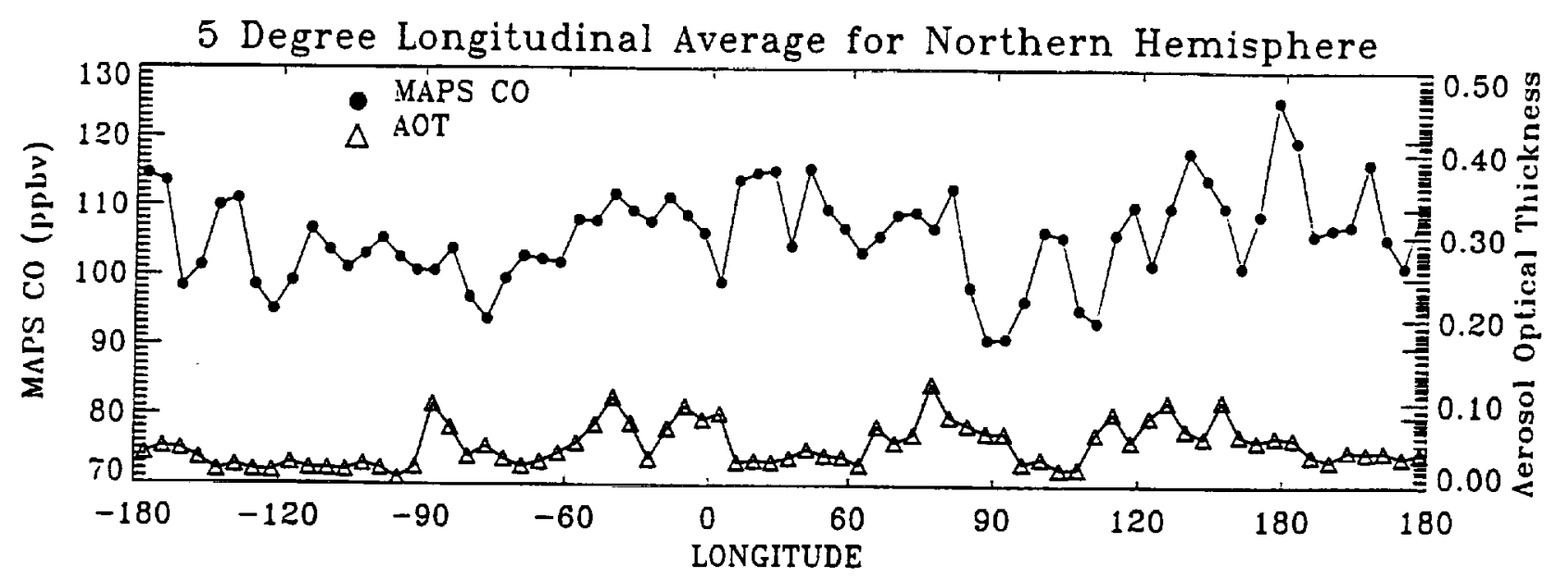

Fig. 3: Longitudinal distribution of aerosol optical thickness and MAPS-measured carbon monoxide.

with horizontal transport due to the prevailing winds, are responsible for the observed spatial distribution of $\mathrm{CO}$.

\section{References.}

[1] Andreae, M.O., Biomass burning: Its history, use, and its distribution and its impact on environmental quality and global climate, In Global Biomass Burning, J.S. Levine, ed., 1-21, 1991.
[2] Andreae, M.O., Global distributuion of fires seen from space. EOS Trans., AGU, 74(13), 129-130, 1993.

[3] Eidenshink, J.C., and J.L. Faundeen, The $1 \mathrm{~km}$ AVHRR global land data set: First stages of implementation. Int. J. Rem. Sens., 15, 3443-3462, 1994.

[4] Rao, C.R.N., L.L. Stowe and E.P. McClain, Remote sensing of aerosol over the oceans using AVHRR data, theory, practice, and applications. Int. J. Remote Sensing, 10, 743-749, 1989. 
